\title{
A Histone Cycle
}

\author{
Douglas Maya, Macarena Morillo-Huesca, \\ Lidia Delgado Ramos, Sebastián Chávez and \\ Mari-Cruz Muñoz-Centeno
}

Additional information is available at the end of the chapter

http://dx.doi.org/10.5772/53993

\section{Introduction}

Each time a cell divides it must duplicate its DNA content and segregate it equally between two daughter cells. Once a cell has decided to replicate its DNA, hundreds of different proteins must carefully interact with each other in a very orchestrated process. Defects in any of these steps can lead to cell death and genetic instability and have been shown to be present in many human diseases including cancer [1]. Each step of DNA replication must take place in a correct spatial and temporal window, so cells have evolved complex regulatory networks allowing an efficient regulation of this process. One important feature of eukaryotic cells is that DNA is strongly associated with histones, basic proteins that wrap DNA around octameric structures called nucleosomes. The association of DNA and nucleosomes is commonly known as chromatin.

Nucleosomes are, among others, one of the principal differences between eukaryotic and prokaryotic DNA. Unlike bacteria, eukaryotic cells are not able to live without DNA packed into chromatin [2]. Replication involves dramatic changes in the whole chromatin landscape, since nucleosomes must be removed transiently from the front of the replication machinery and repositioned after it. Nucleosome disassembly and assembly involves the action of chromatin remodeling factors, proteins able to destabilize interactions between histones and DNA allowing the interaction of other complexes with DNA. Restoration of chromatin after the replication bubble is a very important step because nucleosomes are not repetitive units of information and contain a specific epigenetic signature or code [3]. In order to ensure enough histones for the nascent DNA, cells must increase the pool of free histones. In human cells, each passage through S-phase requires the synthesis and assembly of almost 30 million nucleosomes that are synthesized mainly during S-phase and are rapidly packaged 
to DNA. Histone production is very tightly coupled to DNA synthesis and is rapidly shut off when replication finishes or is halted by treatment with mutagenic agents. Histone regulation is very important and accumulation of free histones in the cell has been shown to be highly deleterious for the cell and lead to chromosome loss [2].

Chromatin is a structural barrier for replication but can also play an important role in the regulation of some of the steps within. In this chapter, we will focus on how the chromatin landscape influences DNA replication and show that histones and DNA must adapt to each other in order to ensure a correct genomic duplication. We will describe the influence that chromatin plays at the different stages of DNA replication and then jump to the accurate control that cells exert on histone levels during the cell cycle. We will finally show different situations that uncouple DNA replication from histone deposition and synthesis, and discuss if chromatin state can influence the decision of cells to replicate their DNA or not.

\section{Replication from a chromatin point of view}

\subsection{Chromatin influences early steps of replication}

The initiation of DNA replication in any organism requires a series of proteins able to recruit and ultimately load two hexameric DNA helicases. These proteins are able to unwind DNA, a process required to start replication. In eukaryotic cells the pre-initiation complex is formed by two MCM2-7 rings that are loaded in an inactive form next to the Origin Recognition Complex (ORC). The MCM helicase must be activated by the sequential action of Dbf4 Dependent Kinase (DDK) and Cyclin Dependent Kinase (CDK), and the addition of other accessory proteins. In mammalian cells, 30,000 to 50,000 origins are sequentially activated each time a cell divides [4].

The nature of the sequence and the structure of replication origins is still a matter of debate, and most higher eukaryotes lack a specific consensus sequence for ORC binding. Origins of DNA Replication Initiation (ORIs) are normally regions of DNA sequence rich in AT that contain a nucleosome-free region (NFR) [5] [6] and it has been suggested that the chromatin environment is important for the establishment of the ORC complex [7] [8]. In Drosophila follicle cells histones that localize around ORIs are hyperacetylated and changes in the acetylation levels of these histones affects ORC binding [9].

As ilustrated in figure 1, methylation of histone $\mathrm{H} 4$ has also been shown to be important for ORC recruitment and artificial tethering of the methyltransferase SET8 to a random locus promotes ORC1 binding [10]. Once ORC is bound to DNA, proteins CDC6 and CDT1 help to load the two MCM2-7 helicases to DNA [11]. Loading could also be influenced by the acetylation of histone $\mathrm{H} 4$, since CDT1 is able to recruit the histone acetyltransferase HBO1 to the ORC and enhances the recruitment of MCM2-7 to the origin [12, 13] [14]. Nevertheless, some ORC and MCM subunits are acetylated by Hbo1 in yeast and could therefore be the real targets of this enzyme [14]. Although all origins that are selected are able to load the pre-initiation complex, only one out of every ten will fire. Regulation of firing depends on 
the activation of the MCM helicases by sequential phosphorylation of some of its subunits by DDK and CDK kinases, that allow the recruitment of CDC45 and the GINS complex [15]. Once these proteins are loaded, the rest of the replication machinery is recruited and replication starts.



Figure 1. Chromatin influences DNA replication fork establishment. Schematic representation of the different steps during the assembly and activation of the replication fork machinery that are influenced by histone modifications. 1.ORC recruitment is influenced by methylation and acetylation levels of histone I-14. 2.Acetylation of histone $\mathrm{H} 4$ by the Hbo1 might influence loading of the two Mcm2-7 helicases. 3. H4K 16 aoetytation is related to the timing of origin firing distribution.

Two interesting observations have lead to the hypothesis that chromosome architecture can also be important for origin usage. One of them is that origins seem to be organized into clusters of 5 to 10 origins that fire simultaneously [18]. Cohesins are enriched next to origins and depletion of the RAD21 cohesin subunit greatly reduces the number of active origins. This ring-like complex is able to wrap two chromatin fibers and creates a chromatin loop. It has been suggested that this spatial organization of chromatin could define replication domains that are activated synchronously [16, 17]. In agreement with this hypothesis, analysis of the oriGNA13 replication origin of hamster cells shows that active origins localize close to the base of chromatin loops [18]. The second feature that directly relates chromatin structure 
and replication is that genome replication does not take place in a single and continuous way. Domains containing several megabases of contiguous DNA are replicated earlier than others [19] and this replication timing is somehow correlated with acetylation levels of histone $\mathrm{H} 4$ at the $\mathrm{K} 16$ residue [20].

Chromatin influences the recruitment and the activity of different elements of the replication machinery. Once this machinery has been set up and is fully active, fork progression must now cope with the fact that approximately every $192 \mathrm{bp}$ there is a nucleosome that must be displaced from DNA in order to continue with replication.

\subsection{Nucleosome reorganization around the replication fork}

Replication fork progression involves many proteins that interact closely with DNA. Electron micrography of replicating SV40 mini-chromosomes has shown that 300bp ahead of the replication fork, DNA remains naked, or at least contains nucleosomes that are unstable when compared to a canonical nucleosome [21] [22]. MCM progression in mammalian cells suggests that chromatin is decondensed in front of the replication fork [23] and artificial tethering of Cdc45 to DNA is able to promote a partial decondensation of chromatin without DNA synthesis [24]. This initial decondensation could be related to an increase in the mobility of histone $\mathrm{H} 1$ due to its phosphorylation by the cyclin A-CDK2 complex. It is still unclear if nucleosome disruption in front of the replication fork is due to specific chromatin remodeling in front of the fork or to the passage of the replication machinery itself [3].

Nucleosome disassembly and reassembly are processes quite well described for transcription. The efficiency of these processes is largely dependent on chromatin-remodeling complexes, proteins able to interact with and change the stability of chromatin, allowing the transcription machinery to interact with DNA. There are many different chromatin-remodeling complexes and all of them are possible candidates for nucleosome eviction during replication. The fact that chromatin disassembly and assembly occur in such a small spatial window makes it very difficult to distinguish between the complexes required for one or the other process. There are two major complexes that could be involved in $\mathrm{H} 2 \mathrm{~A} / \mathrm{H} 2 \mathrm{~B}$ displacement during replication: FACT and NAP1, and another two for H3/H4: Asf1 and CAF1.

The FACT complex is composed of two main subunits, SPT16 and SSRP1 (Pob3 in S.cerevisiae), and plays a key role in nucleosome reorganization during transcription elongation. FACT function has been mostly related to the displacement of an $\mathrm{H} 2 \mathrm{~A} / \mathrm{H} 2 \mathrm{~B}$ dimer during transcription, but it has also been proposed that displacement could be an indirect effect of nucleosome reorganization by this complex [25, 26]. There are many different items of evidence suggesting that FACT plays a role as a histone chaperone during DNA replication. FACT is required for DNA replication in Xenopus extracts, is present at human replication origins [27] and has been co-purified as part of the replication fork progression complex in yeast [28]. The other $\mathrm{H} 2 \mathrm{~A} / \mathrm{H} 2 \mathrm{~B}$ histone chaperone candidate is Nap1, which has been shown to disassemble nucleosomes in vitro when combined with the RSC complex $[29,30]$. Once $\mathrm{H} 2 \mathrm{~A} / \mathrm{H} 2 \mathrm{~B}$ dimers are displaced, the $\mathrm{H} 3 / \mathrm{H} 4$ tetramer is now accessible for an $\mathrm{H} 3 / \mathrm{H} 4$ chaperone. 
To date, it is not known if $\mathrm{H} 2 \mathrm{~A} / \mathrm{H} 2 \mathrm{~B}$ dimers removed during replication are recycled. On the contrary, it is well established that the original H3/H4 tetramer present in front of the replication fork machinery is restored after the replication fork in a random semi-conservative process [31]. The fact that the $\mathrm{H} 3 / \mathrm{H} 4$ tetramer is recycled suggests that a histone chaperone must disassemble this tetramer in front of the replication machinery and reassemble it after. One good candidate for this process is Asf1. This protein along with Chromatin Assembly Factor 1 (CAF1) plays a key role in deposition of new $\mathrm{H} 3 / \mathrm{H} 4$ following passage of the replication fork. Asf1 binds PCNA and replication factor C [32], and can also bind the MCM helicase complex through histones $\mathrm{H} 3$ and H4. Upon a replication fork progression block, Asf1 can be found associated with post-translationally modified $\mathrm{H} 3 / \mathrm{H} 4$ histones, which most likely belong to the parental chromatin [33].

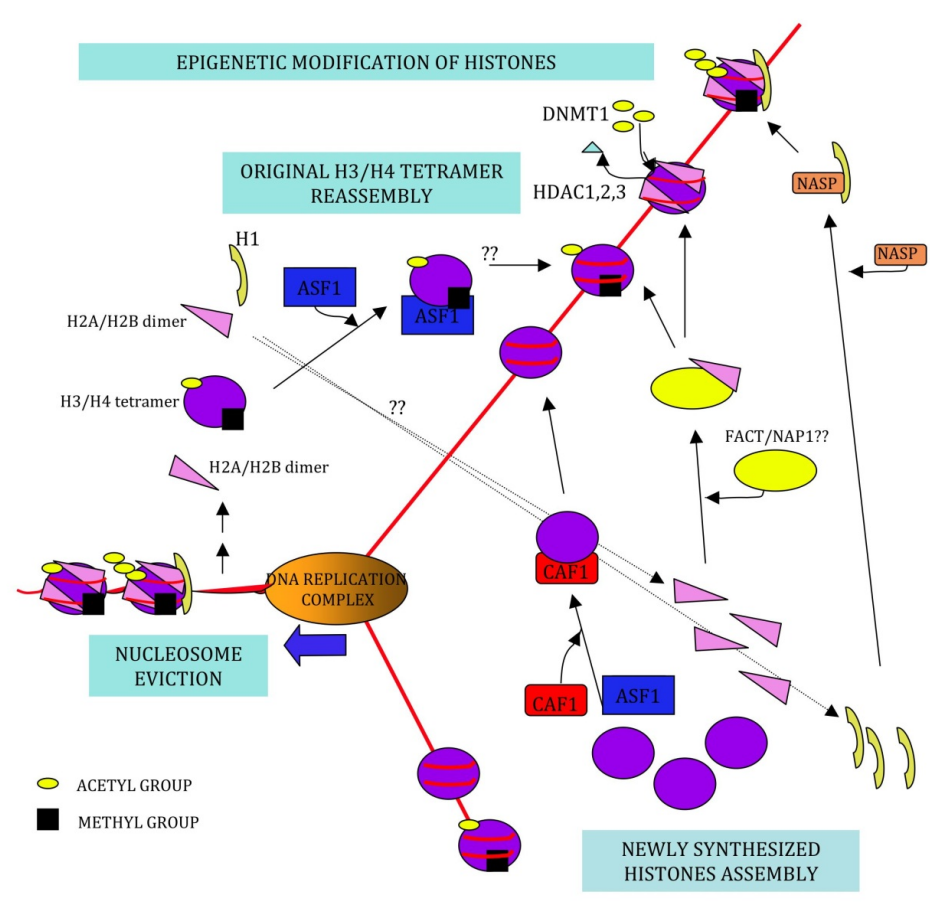

Figure 2. Nucleosome reorganization around the replication fork. Representation of the different nucleosome reorganization events that take place during replication fork progression. In order to simplify the figure, the DNA replication machinery and other accessory proteins that are important during fork progression are not shown. Interrogation marks are used when the protein/s involved in such process remain unknown or when the pathway has not been directly demonstrated.

Deposition of histone octamers occurs as soon as DNA is long enough to wrap around a nucleosome [21]. Since one H3/H4 tetramer is recycled after DNA replication, one new $\mathrm{H} 3 / \mathrm{H} 4$ tetramer must be deposited on the other strand. The mechanism of reposition of the original 
$\mathrm{H} 3 / \mathrm{H} 4$ tetramer remains unclear but probably involves Asf1 (see previous paragraph). Incorporation of the new $\mathrm{H} 3 / \mathrm{H} 4$ tetramer on the other hand is more defined and involves the action of CAF1 and Asf1. CAF1 is recruited to both leading and lagging strands by the proliferating cell nuclear antigen PCNA. Depletion of CAF1 produces a clear decrease in the assembly of new chromatin during replication [34], activates the DNA Damage Checkpoint (DDR), and stalls replication forks [35], suggesting that efficient chromatin repositioning after replication is important for replication fork progression. Asf1 plays a role in this process as a histone pool protein that delivers $\mathrm{H} 3 / \mathrm{H} 4$ dimers to $\mathrm{CAF} 1$. After the $\mathrm{H} 3 / \mathrm{H} 4$ tetramer is assembled, H2A/H2B becomes incorporated into chromatin in a process that probably involves FACT or NAP1. Finally, H1 protein is incorporated to allow further compacting of chromatin. Incorporation of H1 is probably mediated by the NASP protein and is required for efficient S-phase progression [36].

One interesting feature recently described is that the chromatin landscape influences the length of the Okazaki fragments synthesized at the lagging strand during DNA replication [37]. Due to the 5'to 3' polarity of DNA polymerase, synthesis of DNA in the lagging strand is discontinuous and generates short fragments of DNA named Okazaki fragments. These fragments must then join to form a unique DNA strand in a process known as maturation. Okazaki fragment maturation requires the sequential action of the flap endonuclease 1 (FEN1) and DNA ligase I. This group has demonstrated that the ligation junctions of Okazaki fragments are preferentially located in the nucleosome midpoint. The length of Okazaki fragments depends on the chromatin behind the replication fork and mutations that impair chromatin repositioning increase the average size of Okazaki fragments. According to their model, Pol ' runs into the nucleosome assembled into the previous Okazaki fragment and this triggers termination, flap processing and ligation.

\subsection{Chromatin maturation and centromere formation}

After nucleosome incorporation to DNA, two major processes must take place: chromatin maturation and centromere formation. Histones start to acquire certain modifications in their tails as soon as they are repositioned to DNA. Nascent chromatin is highly acetylated and must be deacetylated and methylated to reach a more compact state. Deacetylation normally takes place by the histone deacetylases HDAC1-3 and DNA methylation by the DNA methyltransferase 1 (DNMT1). In addition to chromatin compacting, there are also some specific post-transcriptional modifications that must be acquired to establish a specific epigenetic code that is transmitted to daughter cells. Maintaining this "epigenetic memory" of daughter cells is important and has implications during cell differentiation (23). Restoration of all these marks does not take place exclusively in replication and can also take place during mitosis or even in daughter cells [38, 39]. Replication of the chromatin near the centromere is also vital to ensure an efficient segregation during mitosis. This heterochromatin presents a specific variant of histone $\mathrm{H} 3$ named CENP-A, which is essential for the efficient binding of the kinetochore during mitosis. The kinetochore is a huge structure that attaches to centromeric DNA and mediates the interaction of chromosomes with the mitotic spindle 
and their movement to the spindle poles during mitosis [40]. Accurate segregation of chromosomes relies on the correct formation of the spindle apparatus.

CENP-A (also known as CENH3) is an essential protein that replaces histone $\mathrm{H} 3$ at centromeric DNA. This protein is highly divergent among different species but is functionally well conserved since the homologue protein of S. cerevisiae, Cse4 is able to complement human cells lacking CENP-A or vice versa [41]. In human cells, CENP-A is not assembled on to DNA just after DNA replication and CENP-A-containing nucleosomes are interspersed with canonical nucleosomes during replication of centromeres [42,43]. This organization promotes the folding of centromeric chromatin into a unique structure during metaphase, in which all the nucleosomes containing CENP-A are facing the external side of chromosomes. This structure allows kinetochore assembly and microtubule attachment and favours sister chromatid cohesion [44]. Once chromosomes are separated, CENH3 is fully positioned on centromeric chromatin during the period between telophase and G1 in a process that is dependent on the transient incorporation of Mis18 and KNL2 in anaphase [45]. The incorporation of CENP-A to centromeric chromatin is mediated at least in part by the HJURP protein (Scm3 in S. cerevisiae) and is related to low levels of acetylation of the K16 residue of histone H4. Defects in the proper incorporation of this histone variant can lead to cell death, genetic instability and chromosome loss [46-48]. There is also a subset of specific proteins important to prevent the deposition of CENH3 containing nucleosomes out of the centromeric DNA. In S. cerevisiae, the ubiquitin E3 ligase Psh1 prevents the spread of Cse4 containing nucleosomes out of the centromere [49] [50]. The absence of both CAF1 and HIRA also leads to the presence of this type of nucleosomes in euchromatic regions in both S. cerevisiae and S. pombe and has been shown to cause genetic instability [51]. Finally, several papers point out that a proper homeostasis between $\mathrm{H} 3$ and CENH3 histones is important for the distribution of this centromeric variant and for efficient chromosome segregation $[52,53]$.

\section{From gene to protein, histones are highly regulated}

It is clear that there is a strong interdependency between DNA replication and chromatin reorganization. Nucleosomes are more than structural bricks for DNA, and require the modification of specific residues or the substitution of certain histone variants for others to maintain a correct epigenetic state. Once cells have decided to replicate their DNA, an increase in the abundance of histone proteins is required to pack the new genome that is about to be generated. Histone genes are among the most highly cell-cycle-regulated genes [54] because cells need to ensure a high demand of histones during replication, but must make sure that these levels are quickly down-regulated when replication slows down or is blocked, to avoid the deleterious effects of free histones on cell survival.

Canonical histone proteins can be regulated at transcriptional, post-transcriptional, translational and post-translational levels. The importance of each pathway on histone metabolism largely depends on the organism. In S. cerevisiae for example, the transcriptional regulation has been traditionally shown to play a major role in histone regulation, while in mammalian 
cells, post-transcriptional and translational mechanisms seem to be more important. Nevertheless, it is clear that all organisms try to produce histones exclusively during the replicative S-phase and more specifically only when replication is actively taking place.

\subsection{Histones are regulated from the beginning: transcriptional regulation}

Histone transcription is tightly regulated during the cell cycle. In some organisms like S. cerevisiae, transcription of histones can only be detected in late G1 and during DNA replication [55]. In higher eukaryotes, however, histones mRNAs can be found at all stages but increase as cells enter S-phase [56]. Expression of all canonical histones must be stoichiometric and several studies show that an imbalance between the different histone subtypes can be highly deleterious for the cell $[52,53,57]$.

In metazoans, entry into S-phase increases the expression of replication-dependent histone genes three to five-fold [58]. Histone genes are clustered and each cluster normally contains at least one copy of the five canonical histones. Although transcription of all histones is carefully coordinated, no obvious common sequence element has been found at their promoters. Nevertheless, common elements can be found for some particular histone variants, like the Octamer-binding Transcription Factor (OTF1) for H2B promoters [59] or the Coding Region Activating Sequences (CRAS) in H2A, H3 and H4 genes [60]. Activation of histone gene transcription requires the Nuclear Protein Ataxia-Telangiectasia (NPAT), which is essential for S-phase progression [61]. This protein normally locates next to the Histone locus bodies and is phosphorylated by cyclin E-CDK2 at the beginning of S-Phase. Phosphorylation persists through S-phase and increases histone gene transcription [62, 63].

Transcriptional regulation of histones in S. cerevisiae is largely dependent on the integrity of the HIR complex. This complex is conserved from yeast to humans and has been shown to play a role in both of them in replication-independent chromatin assembly. In yeast, this complex is composed of the three subunits Hir1-3 and Hpc2. Deletion of any of the subunits leads to a de-repression of histones outside of S-phase [64]. Histone genes are grouped in 4 clusters, and each of them express simultaneously $\mathrm{H} 2 \mathrm{~A} / \mathrm{H} 2 \mathrm{~B}$ or $\mathrm{H} 3 / \mathrm{H} 4$ from a bidirectional promoter. These promoters contain upstream activating sequences (UAS) required for the recruitment of activators such as Spt10 and SBF [65]. Three of these four clusters also contain a negative regulatory site (NEG or CCR) able to maintain these genes in a repressed state in cell cycle phases outside of late G1 and Sphase and under replication stress conditions [64, 66, 67]. Deletion of the negative regulatory site is able to de-repress the HTA1-HTB1 histone locus and allow expression outside of S-phase. The mechanism of repression is not completely understood but involves changes at the chromatin structure creating a repressive chromatin, which depends on the HIR complex, proteins Rtt106, Yta7 and Asf1, and the chromatin remodelling complex RSC. Two recent reports coming from the same group have shed some light on how repressive chromatin switches to active chromatin (in terms of transcription). The first one involves the degradation of Yta7 mediated by a phosphorylation event that involves Casein Kinase II (CKAII) and the cyclin-dependent kinase Cdc28. Degradation of Yta7 allows the efficient expression of histone mRNAs during S-phase 
through a mechanism that could involve transcription elongation efficiency [68]. The second report is related to the cell cycle regulation of Spt21, an activator of histone gene expression [69]. Spt21 protein levels outside S-phase are regulated by proteolysis, in a mechanism that depends on a complex formed by the Anaphase Promoting Complex (APC) with Cdh1 during G1, and on APC-Cdc20 during G2 and M (Brenda Andrews, EMBO transcription meeting 2012).

It has been recently shown that the HIR complex is conserved through evolution [70, 71] [55]. In humans, this complex is formed by three proteins: HIRA, Ubinuclein1 and Cabin1. The role described for HIRA in humans has been mostly associated with chromatin assembly of the transcriptional histone variant H3.3 in cooperation with ASF1 [72]. Nevertheless, several studies suggest that this complex could also play an important role in metazoan histone regulation. Ectopic over-expression of HIRA is able to repress histone gene transcription and block S-phase progression in human cells. This protein localizes to histone gene clusters in an immunofluorescence essay [73]. Cyclin E-CDK2 and cyclin A-CDK2 can phosphorylate HIRA, and this phosphorylation is inhibited by cyclin inhibitor p21, which has been shown to be important for repression of histone synthesis upon replication stress [74] [69]. HIRA could therefore be acting as a repressor of histone gene expression outside of Sphase regulated through phosphorylation by the cyclin E-CDK2. In this model, phosphorylation by the cyclin E-CDK2 could switch histone expression by activating NPAT and inactivating HIRA.

\subsection{Once they are transcribed: post-transcriptional and translational regulation}

Mammalian histone mRNAs lack introns and do not have a poly(A) tail as do most mRNAs. Instead, they contain a special 3'UTR sequence that forms a stem-loop structure [54]. Histone clusters localize to specific Cajal Bodies that are enriched in factors required for expression (NPAT) and maturation (U7 snRNA) of histone mRNA named histone locus bodies [75]. Maturation requires the formation of the 3 'end through an endonucleolytic cleavage that has been shown to be important for transcription termination [76, 77]. Cleavage takes place between the stem-loop and the histone downstream element (HDE). The machinery involved in this process uses some common elements from the processing machinery of polyadenylated mRNAs but has also some specific components like SLBP, the Sm-like proteins (LSM1-11), the U7 snRNA and ZFP100. Additional information on maturation of histone mRNAs can be found in a nice review published some years ago [54]. The Stem Loop Binding Protein, SLBP, is one of the most important proteins for post-transcriptional and translational regulation of histone mRNAs and accompanies histone mRNA throughout its life.

SLBP is the only known cell cycle regulated protein of all the histone processing machinery. This protein starts accumulating during late G1 and is degraded at the end of S-phase by the phosphorylation of two threonine residues that target it for degradation [78]. There are three major roles for SLBP on histone regulation: 1. Allow an efficient cleavage during mRNA maturation 2. Facilitate circularization of histone mRNAs, required for their efficient translation by polyribosomes $[79,80]$ and 3 . Increase histone mRNA stability preventing degradation of histone mRNAs by the 3'hExo [81]. Nevertheless, histone mRNA are still degraded when 
SLBP is artificially present at constitutive levels at the end of S-phase [78] or when DNA replication is inhibited [82], indicating that although this protein has a major contribution to histone mRNA stability, it is not able to prevent degradation itself.

Canonical histone mRNAs in lower eukaryotes and plants are polyadenylated. The fact that these transcripts lack any known specific structure at their 3'end and have a short half-life has lead to the conclusion that regulation in these organisms mostly takes place at a transcriptional level. Nevertheless, there is quite a lot of recent evidence that strongly suggests the importance of the post-transcriptional regulation of histone mRNAs in $S$. cerevisiae. Several reports implicate some of the components of the exosome in the specific degradation of the H2B transcripts [83]. One year ago, Herrero and Moreno revealed the importance of the SM-like protein Lsm1 in histone mRNA degradation. Mutants lacking Lsm1 are sensitive to DNA damaging drugs and histone over-expression, and show a defect in histone mRNA degradation under replication stress conditions [84]. This protein is part of the Lsm1-7-Pat1 mRNA degradation complex, which has an important role in histone mRNA degradation under replication stress conditions in human cells. Lsm1-7-Pat1 has been shown to bind preferentially mRNAs carrying U-tracts in human cells, and oligoadenylated over polyadenylated mRNAs in yeast [85, 86]. Upon DNA replication arrest, histone mRNAs in human cells suffer an oligouridylation process acquiring a terminal oligo U-tract required for an efficient degradation by this complex [87]. Uridylation of mRNA has not been detected to date in S. cerevisiae but there is a recent report showing that the average length of the poly(A) tail of the yeast H2B histone mRNA is quite short compared to other transcripts. The length of this poly(A) is cell cycle-dependent and seems to decrease as cells exit G1 and progress through S-phase up to G2, when some of the transcripts completely lack a poly(A) tail [88]. This difference in length opens a possible explanation as to how the Lsm1-7 yeast complex preferentially recognizes yeast histone mRNAs over other transcripts to degrade them at the end of Sphase.

\subsection{Last frontier of histone regulation: controling protein levels}

In addition to the tight regulation of histone mRNA levels, a mechanism able to control histone protein levels was described some years ago [89]. To date, this pathway has only been described in the yeast $S$. cerevisiae and involves the action of the yeast homologue of CHK2, Rad53. Rad53 plays an important role in the DNA Damage Response and has been shown to be essential upon DNA damage or replication stress [1,90]. Histone degradation involves the direct action of Rad53 along with the E2 ubiquitin ligases (UL) Ubc4 and Ubc5 and the E3 UL Tom1 [91]. This complex is able to degrade histones in a mechanism that involves tyrosine phosphorylation and poly-ubiquitylation, before their proteolysis by the proteasome. Histone degradation is independent on the central DNA damage checkpoint signal, since it does not depend on other kinases involved in the DDR like Mec1 (ATM) or Tel1 (ATR). Further studies in higher eukaryotes need to be done to confirm if this pathway is conserved in all eukaryotes. 


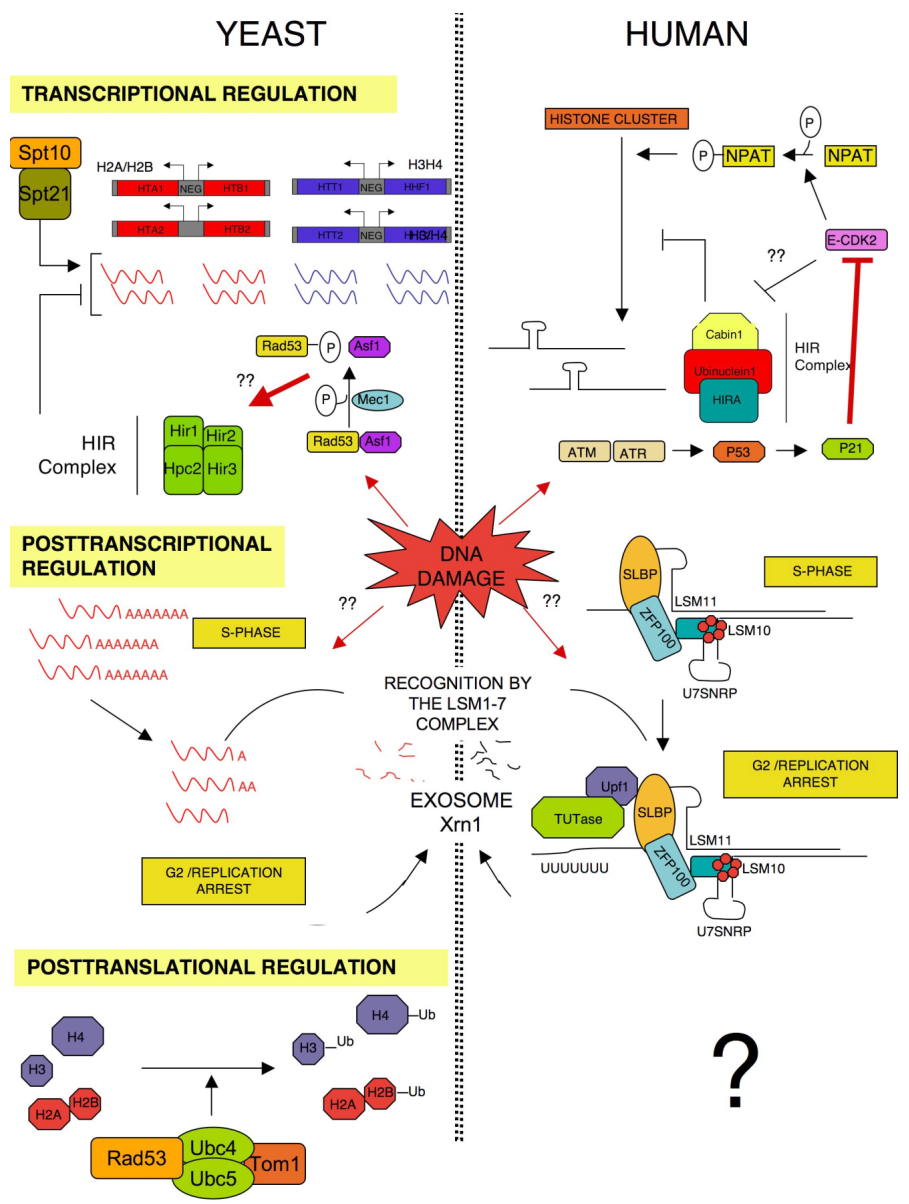

Figure 3. Regulation of histone levels in S.cerevisiae and H.sapiens. Different mechanisms able to control histone levels in S.cerevisiae and H.sapiens. Arrows normally indicate a positive effect on the pathway and straight lines a negative One. Interrogation marks are used when the protein/s involved in such process remain unknown or when the pathway has not been directly demonstrated. The big interrogation mark shown for post-translational regulation in the H.sapiens column, remarks that this pathway has not been demonstrated to date in human cells.

\section{Histones: Enough to pack but not too much}

Histone levels are regulated as soon as transcription of its mRNA starts. On top of the normal cell cycle regulation, additional mechanisms are able to block histone production when replication slows down or is completely blocked. Eukaryotic cells are unable to live without histones [92] and inhibition of histone deposition behind the replication fork blocks DNA synthesis and activates the DNA Damage Response (DDR) [35]. Eukaryotes seem to have 
evolved to a situation in which histones must not be free in the cell and DNA must not be free of histones. In this last part of the chapter, we will focus on how cells cope with situations that break this bidirectional relationship.

\subsection{Harmful effects of free histones}

Histones are basic proteins that can bind-specifically to negatively charged molecules. Reconstitution experiments show that a slight excess of histones over DNA is sufficient to promote chromatin aggregation, probably due to the neutralization of negative charged DNA. In yeast, high levels of histones increase chromosome loss and enhance DNA damage sensitivity $[57,89]$. Defects in histone degradation during replication stress or DNA damage severely decreases cell viability [84]. Free histones show electrostatic interactions with some cellular macromolecules carrying the opposite charge such as RNA molecules. Additionally, an excess of free histones can saturate and inhibit the activity of some histone modifying enzymes, and change the expression pattern of almost 240 genes [93]. Two different studies in the yeasts S. cerevisiae and Schizosaccharomyces pombe have demonstrated the importance of a correct balance between histone $\mathrm{H} 3$ and the centromeric variant Cse4 (CENPA) for efficient chromosome segregation. $\mathrm{H} 3$ can compete with Cse4 in the assembly of centromeric chromatin and this competition largely depends on a correct balance between levels of $\mathrm{H} 3$ and H4 $[52,53]$. Cells must therefore not only prevent the accumulation of free histones but also ensure a correct homeostasis between canonical and other histone variants. Once cells have decided to initiate replication, any problem that unbalances replication fork progression with histone levels can potentially lead to an increase in the abundance of free histones. In order to prevent this, there is an additional pathway linked to the DDR able to block histone synthesis under DNA replication stress conditions or replication fork arrest.

\subsection{The DNA Damage Response (DDR): Coupling DNA and histone synthesis}

DDR is probably one of the most well characterized checkpoints in the cell and is normally activated whenever a cell senses DNA damage. Activation leads to the sequential action of a cascade of kinases that block or delay cell cycle progression to allow the cell to correct the damage. If damage cannot be repaired, human cells enter the apoptosis program and die [94]. Proper functioning of this pathway is essential for genome integrity and mutations in most of the branches of this path are linked to cancer and other diseases. DDR is able to block cells at G1, S and G2/M [95]. In human cells, two kinases ATM and ATR (Tel1 and Mec1 respectively in S. cerevisiae) play a major role in the activation of the DDR. ATM has been directly involved in the activation of a mechanism that ultimately leads to repression of histone expression.

In human cells, activation of histone gene transcription requires NPAT phosphorylation by the cyclin E-CDK2 complex at the beginning of S-Phase. Activation of NPAT is essential for S-phase progression and histone expression. Repression of histone synthesis upon DNA damage requires the activation of ATM, which leads to the sequential activation of p53 and then p21. p21 is able to block the activity of the cyclin E-CDK2 complex. Inhibition of this complex leads to a progressive dephosphorylation of NPAT, which no longer localizes to 
histone clusters to activate transcription [96]. One interesting hypothesis that remains to be tested is if this cascade could also lead to histone repression by a change in the activity or location of HIRA, the human homologue of the HIR complex, at histone promoters (see previous paragraph about transcriptional regulation of histones). DNA damage also promotes post-transcriptional degradation of histone mRNAs. Treatment of cells with hydroxyurea (HU) increases oligouridylation of histone mRNAs in a process that depends on Upf1. Upf1 binds SLBP and helps to recruit a 3' Terminal Uridylyl Transferase (TUT-ase) required for oligourydilation. These $3^{\prime}$ oligo(U) tails are recognized by the Lsm1-7 complex that triggers mRNA degradation through the exosome and Xrn1 [87]. How Upf1 is recruited to histone mRNAs upon DNA damage remains unknown.

Regulation of histone levels upon DNA damage in S. cerevisiae shows some common regulatory elements with human cells, and suggests the existence of a conserved mechanism. Posttranscriptional regulation also depends on the Lsm1-7 complex. It is not clear how this complex recognizes histone mRNAs but it could be related to the poly (A) tail-length (see post-transcriptional regulation of histones). Post-translational regulation by the Rad53 histone degradation pathway has not been directly addressed during the DDR, but taking into account the role of this protein in both pathways, it is reasonable to think that Rad53 could be important to destroy the population of translated histones when replication is halted. There are no NPAT homologues described in yeast and negative regulation during the DDR depends on the integrity of the HIR complex. The repressive structure formed to block transcription on histone promoters also requires Asf1 and Rtt106 among others. Although there is a lot of information about the formation of the repressive structure created at the promoter [97], the first steps by which DNA damage triggers histone repression remain largely unknown. There is some data nevertheless that suggest that Asf1 and Rad53 could play a role in this process.

Asf1 is able to form a very stable complex with Rad53. Upon activation of the DNA damage response, Mec1 phosphorylates Rad53 and this phosphorylation dissociates the stable Asf1Rad53 complex. This mechanism has been linked to a possible connection between checkpoint activation and DNA repair since Asf1 plays a role in chromatin remodeling during DNA repair [98]. Rad53 can also be found in a hypophosphorylated form in normal conditions during G1, G2 and M, stages at which histone transcription is repressed. This phosphorylation seems to depend on Cdc28, the yeast functional homologue of human CDK1 and CDK2. Asf1 is able to co-immunoprecipitate with all the subunits of the HIR complex. This complex has been related to replication-independent nucleosome assembly and in vitro data prove that it is able to assembly nucleosomes to a DNA template [99]. Mutants lacking Asf1 have higher levels of histone mRNA and show defects in S-phase progression [100]. We have recently seen in our lab that mutants lacking the kinase activity of Rad53 also have enhanced levels of these mRNAs (unpublished results). Taking into account the close relationship that Asf1 plays with both Rad53 and the HIR complex, it is possible to think that the dissociation of Rad53 and Asf1 during DNA damage could be important for the efficient repression of histone transcription. 


\subsection{Generation of free histones in the cell}

How can free histones be generated during a normal cell cycle? Taking into account the tight regulation of histone levels, such situations may seem unlikely. There are two scenarios in which it is possible to think that histone supply and DNA replication can be unbalanced during a normal cell cycle. In the first one, this situation could arise from differences between the rate of DNA synthesis and histone supply during replication. Early S-phase cells use more replication forks than late S-phase cells [101, 102] and lesions in DNA or replication stress also affect the speed of the replication fork [103-106]. The second scenario in which a cell can encounter free histones would take place during the G2 stage of the cell cycle. Given the importance of a balanced ratio between histone H3 and CENPA in chromosome segregation, once cells have finished replication, all free histones that are not positioned should be quickly degraded. It is possible to think that an imbalance between these two types of histones could sometimes take place in actively replicating cells and opens a simple explanation to why most cancer cells have a high incidence rate of chromosome loss [107].

\subsection{Transcription as a source of free histones}

Transcription of a chromatin template also requires nucleosomes to be disassembled and reassembled after the passage of RNA polymerase II (RNA Pol II). Outside of the S-phase, transcribed chromatin is probably the major potential source of free histones. These free histones could arise due to minor imbalances between histone supply and demand during chromatin reassembly. One very well described essential factor involved in RNA pol II transcription is the FACT complex [108, 109]. This complex is able to stimulate RNA Pol II-dependent transcription elongation through chromatin in vitro $[110,111]$ and also in vivo [112-114]. FACT is able to bind H3/H4 tetramers and H2A/H2B dimers $[115,116]$ and it has been shown that the integrity of at least one of its subunits, Spt16, is important for an efficient reassembly of the original $\mathrm{H} 3$ and $\mathrm{H} 4$ histones evicted during transcription [117]. Our group, in collaboration with others, demonstrated two years ago that dysfunction in chromatin reassembly during transcription due to defects in the Spt16 protein generates an accumulation of free histones in yeast. Combination of this mutant with a kinase dead version of $\operatorname{Rad} 53\left(\mathrm{rad} 53 \mathrm{~K}^{227} \mathrm{~A}\right.$ ), unable to efficiently degrade histones, increases the accumulation of free histones and greatly impairs viability of this mutant in a checkpoint-independent way [118]. Deletion of one of the two-histone clusters for H2A-H2B expression is able to partially suppress the growth defect of this mutant and increasing $\mathrm{H} 2 \mathrm{~A}-\mathrm{H} 2 \mathrm{~B}$ expression has the opposite effect. There is a strong correlation between histone levels and viability defects of the chromatin reassembly mutant of Spt16. This defect is not exclusive for Spt16, since Spt6, another chromatin remodeling factor involved in $\mathrm{H} 3-\mathrm{H} 4$ repositioning during transcription, also has a strong negative interaction with rad53K227 A. Chromatin reassembly defects can lead to the generation of free histones evicted from chromatin during transcription, a new source of histones potentially toxic for the cell. Rad53 negatively interacts with many different proteins involved in chromatin-related processes and could have an important function in maintaining chromatin structure in yeast [119]. Some of these interactions are with factors that have 
only been exclusively involved to date in chromatin related processes during transcription $[118,119]$ suggesting that Rad53 could play an important role in the degradation of histones when chromatin is not correctly reassembled during transcription.

\subsection{Can the state of chromatin influence the decision of cells to initiate DNA replication?}

Histones are able to affect DNA replication right from the beginning; the state of the chromatin influences the timing and organization of origin firing. Replication fork progression also depends on the correct histone deposition behind the replication machinery, since defects in CAF1 lead to checkpoint activation and block cells in S-phase. The state of chromatin is able therefore to influence DNA replication. Work done in our lab, suggests that chromatin state might also influence the decision of cells to enter or not replication during the G1/S transition in the S. cerevisiae.

The commitment to a new round of cell division takes place towards the end of the G1 phase of the cell cycle in a process called START in yeast, and Restriction Point in mammals [120]. In yeast, this is the main regulatory event of the G1 phase of the cell cycle and involves an extensive transcriptional program driven by transcription factors SBF (Swi4-Swi6) and MBF (Mbp1-Swi6) [121, 122]. MBF and SBF activation depends on the cyclin/cyclin-dependent-kinase (CDK) complex Cln3-Cdc28. This complex phosphorylates Whi5, the negative regulator of START, thus promoting its release from SBF (Swi4-Swi6). Activation of MBF-dependent transcription by $\mathrm{Cln} 3-\mathrm{Cdc} 28$ acts through a mechanism independent of Whi5, involving the phosphorylation of Mbp1 [123]. Activation of these two complexes results in the accumulation of $\mathrm{G} 1(\mathrm{Cln} 1$ and $\mathrm{Cln} 2)$ and the early S-phase cyclins (Clb5 and Clb6), which promote in last term S-phase entry [124]. The kinase activity of Cln1,2-Cdc28 triggers the degradation of cyclin-dependent kinase inhibitor Sic1 which no longer inhibits the S phase-promoting complex Clb5,6-Cdc28 [125, 126].

FACT plays a role in maintaining the integrity of the chromatin structure during transcription [127-129] but has also been related to a G1/S cell cycle defect in yeast in a genetic screen to identify $c d c$ (cell division cycle) mutants. This cell cycle defect had been linked initially to a general transcription defect of the three G1 cyclins Cln1-Cln3 [130] and later, to a possible important role of FACT in the transcription of CLN1 and CLN2 [131]. We recently described that this G1 defect is also due to a transcriptional downregulation of the cyclin $\mathrm{Cln} 3$ at the promoter level. Surprisingly, FACT seems not to be directly involved in the transcriptional regulation of this cyclin, since it is not recruited to the promoter at START when CLN3 levels are maximal (D. Stillman unpublished results). One rather unexpected but interesting result is that this cell cycle defect shows a direct correlation with histone levels. Decreasing the $\mathrm{H} 2 \mathrm{~A}-\mathrm{H} 2 \mathrm{~B}$ histone pool diminishes the cell cycle accumulation of this mutant while blocking the efficient degradation of histones has an additive effect. This defect is not exclusive for FACT mutants, since an Spt6 mutant also shows cell cycle defects at the G1/S transition [118]. Moreover, in yeast, a structural mutant of histone H4 in a region important for the interaction between the $\mathrm{H} 3-\mathrm{H} 4$ tetramer and the two $\mathrm{H} 2 \mathrm{~A}-\mathrm{H} 2 \mathrm{~B}$ dimers completely mimics the cell cycle defects of the Spt16 mutant [132]. Defects in the chromatin structure seem to be connected somehow to the G1/S transition. Our group has speculated that cells might be 
able to sense the chromatin state before entering a new round of replication. This mechanism would act at least in part through a transcriptional repression of the cyclin $\mathrm{Cln} 3$ mRNA. Although our first results pointed out that free histones could be the signal that triggers this G1/S transition defect, new results obtained by our lab show that this regulation could be more complex and also involve the chromatin structure itself (unpublished results).

\section{Conclusion}

In eukaryotes and also some archaebacteria, DNA forms a nucleoprotein complex called chromatin, which allows extensive compaction of genomic DNA in the limited space of the nucleus. This traditional view of chromatin as simple building-bricks has substantially changed since the nucleosome hypothesis was proposed [133, 134]. Cells have evolved a unique and complex machinery to cope with the fact that most of the processes involving DNA are going to need to interact with and probably modify chromatin first. Chromatin acts as a new step of regulation and carries an epigenetic specific code that in some cases can be as important for the cell as the one contained on DNA. In addition, cells must also carefully balance the levels of histones during chromatin formation to avoid the generation of free histones, in order to prevent their deleterious effects.

\section{Acknowledgments}

We thank Akash Gunjan's and Vincent Geli's labs for our fruitful collaboration. We would also like to thank people in the lab for such a wonderful work environment and to all those people who are always there to make things easier. The Spanish Ministry of Education and Science (grant BFU2007-67575-C03-02/BMC), the Andalusian Government (grant P07CVI02623) and the European Union (FEDER) have supported this work. D.M. was covered by a F.P.I. fellowship from the Regional Andalusian Government, and M. M-H. and L.D-R., by fellowships from the Spanish Ministry of Education and Science.

\section{Author details}

Douglas Maya*, Macarena Morillo-Huesca, Lidia Delgado Ramos, Sebastián Chávez and Mari-Cruz Muñoz-Centeno

*Address all correspondence to: dmaya@us.es

Department of Genetics, Faculty of Biology, University of Seville, Spain 


\section{References}

[1] Jones RM, Petermann E. Replication fork dynamics and the DNA damage response. Biochem J. 2012 Apr 1;443(1):13-26.

[2] Gunjan A, Paik J, Verreault A. Regulation of histone synthesis and nucleosome assembly. Biochimie. 2005 Jul;87(7):625-635.

[3] Alabert C, Groth A. Chromatin replication and epigenome maintenance. Nat Rev Mol Cell Biol. 2012 Mar;13(3):153-167.

[4] Mechali M. Eukaryotic DNA replication origins: many choices for appropriate answers. Nat Rev Mol Cell Biol. 2010 Oct;11(10):728-738.

[5] Xu J, Yanagisawa Y, Tsankov AM, Hart C, Aoki K, Kommajosyula N, et al. Genomewide identification and characterization of replication origins by deep sequencing. Genome Biol. 2012 Apr 24;13(4):R27.

[6] Gao F, Luo H, Zhang CT. DeOri: a database of eukaryotic DNA replication origins. Bioinformatics. 2012 Jun 1;28(11):1551-1552.

[7] Sclafani RA, Holzen TM. Cell cycle regulation of DNA replication. Annu Rev Genet. 2007;41:237-280.

[8] Dohrmann PR, Sclafani RA. Novel role for checkpoint Rad53 protein kinase in the initiation of chromosomal DNA replication in Saccharomyces cerevisiae. Genetics. 2006 Sep;174(1):87-99.

[9] Aggarwal BD, Calvi BR. Chromatin regulates origin activity in Drosophila follicle cells. Nature. 2004 Jul 15;430(6997):372-376.

[10] Tardat M, Brustel J, Kirsh O, Lefevbre C, Callanan M, Sardet C, et al. The histone H4 Lys 20 methyltransferase PR-Set7 regulates replication origins in mammalian cells. Nat Cell Biol. 2010 Nov;12(11):1086-1093.

[11] Kouzarides T. Chromatin modifications and their function. Cell. 2007 Feb 23;128(4): 693-705.

[12] Miotto B, Struhl K. HBO1 histone acetylase is a coactivator of the replication licensing factor Cdt1. Genes Dev. 2008 Oct 1;22(19):2633-2638.

[13] Miotto B, Struhl K. HBO1 histone acetylase activity is essential for DNA replication licensing and inhibited by Geminin. Mol Cell. 2010 Jan 15;37(1):57-66.

[14] Iizuka M, Matsui T, Takisawa H, Smith MM. Regulation of replication licensing by acetyltransferase Hbo1. Mol Cell Biol. 2006 Feb;26(3):1098-1108.

[15] Remus D, Diffley JF. Eukaryotic DNA replication control: lock and load, then fire. Curr Opin Cell Biol. 2009 Dec;21(6):771-777. 
[16] MacAlpine HK, Gordan R, Powell SK, Hartemink AJ, MacAlpine DM. Drosophila ORC localizes to open chromatin and marks sites of cohesin complex loading. Genome Res. 2010 Feb;20(2):201-211.

[17] Guillou E, Ibarra A, Coulon V, Casado-Vela J, Rico D, Casal I, et al. Cohesin organizes chromatin loops at DNA replication factories. Genes Dev. 2010 Dec 15;24(24): 2812-2822.

[18] Courbet S, Gay S, Arnoult N, Wronka G, Anglana M, Brison O, et al. Replication fork movement sets chromatin loop size and origin choice in mammalian cells. Nature. 2008 Sep 25;455(7212):557-560.

[19] Gilbert DM, Takebayashi SI, Ryba T, Lu J, Pope BD, Wilson KA, et al. Space and time in the nucleus: developmental control of replication timing and chromosome architecture. Cold Spring Harb Symp Quant Biol. 2010;75:143-153.

[20] Schwaiger M, Stadler MB, Bell O, Kohler H, Oakeley EJ, Schubeler D. Chromatin state marks cell-type- and gender-specific replication of the Drosophila genome. Genes Dev. 2009 Mar 1;23(5):589-601.

[21] Sogo JM, Stahl H, Koller T, Knippers R. Structure of replicating simian virus 40 minichromosomes. The replication fork, core histone segregation and terminal structures. J Mol Biol. 1986 May 5;189(1):189-204.

[22] Gasser R, Koller T, Sogo JM. The stability of nucleosomes at the replication fork. J Mol Biol. 1996 May 3;258(2):224-239.

[23] Kuipers MA, Stasevich TJ, Sasaki T, Wilson KA, Hazelwood KL, McNally JG, et al. Highly stable loading of Mcm proteins onto chromatin in living cells requires replication to unload. J Cell Biol. 2011 Jan 10;192(1):29-41.

[24] Alexandrow MG, Hamlin JL. Chromatin decondensation in S-phase involves recruitment of Cdk2 by Cdc45 and histone H1 phosphorylation. J Cell Biol. 2005 Mar $14 ; 168(6): 875-886$.

[25] Belotserkovskaya R, Oh S, Bondarenko VA, Orphanides G, Studitsky VM, Reinberg D. FACT facilitates transcription-dependent nucleosome alteration. Science. 2003 Aug 22;301(5636):1090-1093.

[26] Xin H, Takahata S, Blanksma M, McCullough L, Stillman DJ, Formosa T. yFACT induces global accessibility of nucleosomal DNA without H2A-H2B displacement. Mol Cell. 2009 Aug 14;35(3):365-376.

[27] Hertel L, De Andrea M, Bellomo G, Santoro P, Landolfo S, Gariglio M. The HMG protein T160 colocalizes with DNA replication foci and is down-regulated during cell differentiation. Exp Cell Res. 1999 Aug 1;250(2):313-328.

[28] Tan BC, Chien CT, Hirose S, Lee SC. Functional cooperation between FACT and MCM helicase facilitates initiation of chromatin DNA replication. EMBO J. 2006 Sep 6;25(17):3975-3985. 
[29] Ito T, Bulger M, Kobayashi R, Kadonaga JT. Drosophila NAP-1 is a core histone chaperone that functions in ATP-facilitated assembly of regularly spaced nucleosomal arrays. Mol Cell Biol. 1996 Jun;16(6):3112-3124.

[30] Lorch Y, Maier-Davis B, Kornberg RD. Chromatin remodeling by nucleosome disassembly in vitro. Proc Natl Acad Sci U S A. 2006 Feb 28;103(9):3090-3093.

[31] Xu M, Long C, Chen X, Huang C, Chen S, Zhu B. Partitioning of histone H3-H4 tetramers during DNA replication-dependent chromatin assembly. Science. 2010 Apr 2;328(5974):94-98.

[32] Franco AA, Lam WM, Burgers PM, Kaufman PD. Histone deposition protein Asf1 maintains DNA replisome integrity and interacts with replication factor C. Genes Dev. 2005 Jun 1;19(11):1365-1375.

[33] Groth A, Corpet A, Cook AJ, Roche D, Bartek J, Lukas J, et al. Regulation of replication fork progression through histone supply and demand. Science. 2007 Dec 21;318(5858):1928-1931.

[34] Hoek M, Stillman B. Chromatin assembly factor 1 is essential and couples chromatin assembly to DNA replication in vivo. Proc Natl Acad Sci U S A. 2003 Oct 14;100(21): 12183-12188.

[35] Ye X, Franco AA, Santos H, Nelson DM, Kaufman PD, Adams PD. Defective S phase chromatin assembly causes DNA damage, activation of the $S$ phase checkpoint, and S phase arrest. Mol Cell. 2003 Feb;11(2):341-351.

[36] Finn RM, Browne K, Hodgson KC, Ausio J. sNASP, a histone H1-specific eukaryotic chaperone dimer that facilitates chromatin assembly. Biophys J. 2008 Aug;95(3): 1314-1325.

[37] Smith DJ, Whitehouse I. Intrinsic coupling of lagging-strand synthesis to chromatin assembly. Nature. 2012 Mar 22;483(7390):434-438.

[38] Pesavento JJ, Yang H, Kelleher NL, Mizzen CA. Certain and progressive methylation of histone H4 at lysine 20 during the cell cycle. Mol Cell Biol. 2008 Jan;28(1):468-486.

[39] Lanzuolo C, Lo Sardo F, Diamantini A, Orlando V. PcG complexes set the stage for epigenetic inheritance of gene silencing in early $S$ phase before replication. PLoS Genet. 2011 Nov;7(11):e1002370.

[40] Westermann S, Drubin DG, Barnes G. Structures and functions of yeast kinetochore complexes. Annu Rev Biochem. 2007;76:563-591.

[41] Wieland G, Orthaus S, Ohndorf S, Diekmann S, Hemmerich P. Functional complementation of human centromere protein A (CENP-A) by Cse4p from Saccharomyces cerevisiae. Mol Cell Biol. 2004 Aug;24(15):6620-6630.

[42] Jansen LE, Black BE, Foltz DR, Cleveland DW. Propagation of centromeric chromatin requires exit from mitosis. J Cell Biol. 2007 Mar 12;176(6):795-805. 
[43] Schuh M, Lehner CF, Heidmann S. Incorporation of Drosophila CID/CENP-A and CENP-C into centromeres during early embryonic anaphase. Curr Biol. 2007 Feb 6;17(3):237-243.

[44] Black BE, Bassett EA. The histone variant CENP-A and centromere specification. Curr Opin Cell Biol. 2008 Feb;20(1):91-100.

[45] Fujita Y, Hayashi T, Kiyomitsu T, Toyoda Y, Kokubu A, Obuse C, et al. Priming of centromere for CENP-A recruitment by human hMis18alpha, hMis18beta, and M18BP1. Dev Cell. 2007 Jan;12(1):17-30.

[46] Choy JS, Mishra PK, Au WC, Basrai MA. Insights into assembly and regulation of centromeric chromatin in Saccharomyces cerevisiae. Biochim Biophys Acta. 2012 Jul; 1819(7):776-783.

[47] Stoler S, Rogers K, Weitze S, Morey L, Fitzgerald-Hayes M, Baker RE. Scm3, an essential Saccharomyces cerevisiae centromere protein required for G2/M progression and Cse4 localization. Proc Natl Acad Sci U S A. 2007 Jun 19;104(25):10571-10576.

[48] Dunleavy EM, Roche D, Tagami H, Lacoste N, Ray-Gallet D, Nakamura Y, et al. HJURP is a cell-cycle-dependent maintenance and deposition factor of CENP-A at centromeres. Cell. 2009 May 1;137(3):485-497.

[49] Hewawasam G, Shivaraju M, Mattingly M, Venkatesh S, Martin-Brown S, Florens L, et al. Psh1 is an E3 ubiquitin ligase that targets the centromeric histone variant Cse4. Mol Cell. 2010 Nov 12;40(3):444-454.

[50] Ranjitkar P, Press MO, Yi X, Baker R, MacCoss MJ, Biggins S. An E3 ubiquitin ligase prevents ectopic localization of the centromeric histone $\mathrm{H} 3$ variant via the centromere targeting domain. Mol Cell. 2010 Nov 12;40(3):455-464.

[51] Lopes da Rosa J, Holik J, Green EM, Rando OJ, Kaufman PD. Overlapping regulation of CenH3 localization and histone $\mathrm{H} 3$ turnover by CAF-1 and HIR proteins in Saccharomyces cerevisiae. Genetics. 2011 Jan;187(1):9-19.

[52] Castillo AG, Mellone BG, Partridge JF, Richardson W, Hamilton GL, Allshire RC, et al. Plasticity of fission yeast CENP-A chromatin driven by relative levels of histone H3 and H4. PLoS Genet. 2007 Jul;3(7):e121.

[53] Au WC, Crisp MJ, DeLuca SZ, Rando OJ, Basrai MA. Altered dosage and mislocalization of histone H3 and Cse4p lead to chromosome loss in Saccharomyces cerevisiae. Genetics. 2008 May;179(1):263-275.

[54] Marzluff WF, Wagner EJ, Duronio RJ. Metabolism and regulation of canonical histone mRNAs: life without a poly(A) tail. Nat Rev Genet. 2008 Nov;9(11):843-854.

[55] Amin AD, Vishnoi N, Prochasson P. A global requirement for the HIR complex in the assembly of chromatin. Biochim Biophys Acta. 2012 Mar;1819(3-4):264-276.

[56] Jaeger S, Barends S, Giege R, Eriani G, Martin F. Expression of metazoan replicationdependent histone genes. Biochimie. 2005 Sep-Oct;87(9-10):827-834. 
[57] Meeks-Wagner D, Hartwell LH. Normal stoichiometry of histone dimer sets is necessary for high fidelity of mitotic chromosome transmission. Cell. 1986 Jan 17;44(1): 43-52.

[58] Marzluff WF, Duronio RJ. Histone mRNA expression: multiple levels of cell cycle regulation and important developmental consequences. Curr Opin Cell Biol. 2002 Dec;14(6):692-699.

[59] Fletcher C, Heintz N, Roeder RG. Purification and characterization of OTF-1, a transcription factor regulating cell cycle expression of a human histone H2b gene. Cell. 1987 Dec 4;51(5):773-781.

[60] Kaludov NK, Pabon-Pena L, Hurt MM. Identification of a second conserved element within the coding sequence of a mouse $\mathrm{H} 3$ histone gene that interacts with nuclear factors and is necessary for normal expression. Nucleic Acids Res. 1996 Feb 1;24(3): 523-531.

[61] Ye X, Wei Y, Nalepa G, Harper JW. The cyclin E/Cdk2 substrate p220(NPAT) is required for S-phase entry, histone gene expression, and Cajal body maintenance in human somatic cells. Mol Cell Biol. 2003 Dec;23(23):8586-8600.

[62] Ma T, Van Tine BA, Wei Y, Garrett MD, Nelson D, Adams PD, et al. Cell cycle-regulated phosphorylation of p220(NPAT) by cyclin E/Cdk2 in Cajal bodies promotes histone gene transcription. Genes Dev. 2000 Sep 15;14(18):2298-2313.

[63] Zhao J, Kennedy BK, Lawrence BD, Barbie DA, Matera AG, Fletcher JA, et al. NPAT links cyclin E-Cdk2 to the regulation of replication-dependent histone gene transcription. Genes Dev. 2000 Sep 15;14(18):2283-2297.

[64] Spector MS, Raff A, DeSilva H, Lee K, Osley MA. Hir1p and Hir2p function as transcriptional corepressors to regulate histone gene transcription in the Saccharomyces cerevisiae cell cycle. Mol Cell Biol. 1997 Feb;17(2):545-552.

[65] Eriksson PR, Ganguli D, Clark DJ. Spt10 and Swi4 control the timing of histone H2A/H2B gene activation in budding yeast. Mol Cell Biol. 2011 Feb;31(3):557-572.

[66] Osley MA, Gould J, Kim S, Kane MY, Hereford L. Identification of sequences in a yeast histone promoter involved in periodic transcription. Cell. 1986 May 23;45(4): 537-544.

[67] Freeman KB, Karns LR, Lutz KA, Smith MM. Histone H3 transcription in Saccharomyces cerevisiae is controlled by multiple cell cycle activation sites and a constitutive negative regulatory element. Mol Cell Biol. 1992 Dec;12(12):5455-5463.

[68] Kurat CF, Lambert JP, van Dyk D, Tsui K, van Bakel H, Kaluarachchi S, et al. Restriction of histone gene transcription to $S$ phase by phosphorylation of a chromatin boundary protein. Genes Dev. 2011 Dec 1;25(23):2489-2501. 
[69] Dollard C, Ricupero-Hovasse SL, Natsoulis G, Boeke JD, Winston F. SPT10 and SPT21 are required for transcription of particular histone genes in Saccharomyces cerevisiae. Mol Cell Biol. 1994 Aug;14(8):5223-5228.

[70] Balaji S, Iyer LM, Aravind L. HPC2 and ubinuclein define a novel family of histone chaperones conserved throughout eukaryotes. Mol Biosyst. 2009 Mar;5(3):269-275.

[71] Banumathy G, Somaiah N, Zhang R, Tang Y, Hoffmann J, Andrake M, et al. Human UBN1 is an ortholog of yeast Hpc2p and has an essential role in the HIRA/ASF1a chromatin-remodeling pathway in senescent cells. Mol Cell Biol. 2009 Feb;29(3): 758-770.

[72] Tagami H, Ray-Gallet D, Almouzni G, Nakatani Y. Histone H3.1 and H3.3 complexes mediate nucleosome assembly pathways dependent or independent of DNA synthesis. Cell. 2004 Jan 9;116(1):51-61.

[73] Nelson DM, Ye X, Hall C, Santos H, Ma T, Kao GD, et al. Coupling of DNA synthesis and histone synthesis in S phase independent of cyclin/cdk2 activity. Mol Cell Biol. 2002 Nov;22(21):7459-7472.

[74] Hall C, Nelson DM, Ye X, Baker K, DeCaprio JA, Seeholzer S, et al. HIRA, the human homologue of yeast Hir1p and Hir2p, is a novel cyclin-cdk2 substrate whose expression blocks S-phase progression. Mol Cell Biol. 2001 Mar;21(5):1854-1865.

[75] Nizami Z, Deryusheva S, Gall JG. The Cajal body and histone locus body. Cold Spring Harb Perspect Biol. 2010 Jul;2(7):a000653.

[76] Chodchoy N, Pandey NB, Marzluff WF. An intact histone 3'-processing site is required for transcription termination in a mouse histone H2a gene. Mol Cell Biol. 1991 Jan;11(1):497-509.

[77] Gu X, Marzluff WF. 3' Processing and termination of mouse histone transcripts synthesized in vitro by RNA polymerase II. Nucleic Acids Res. 1996 Oct 1;24(19): 3797-3805.

[78] Zheng L, Dominski Z, Yang XC, Elms P, Raska CS, Borchers CH, et al. Phosphorylation of stem-loop binding protein (SLBP) on two threonines triggers degradation of SLBP, the sole cell cycle-regulated factor required for regulation of histone mRNA processing, at the end of S phase. Mol Cell Biol. 2003 Mar;23(5):1590-1601.

[79] Sanchez R, Marzluff WF. The stem-loop binding protein is required for efficient translation of histone mRNA in vivo and in vitro. Mol Cell Biol. 2002 Oct;22(20): 7093-7104.

[80] Gorgoni B, Andrews S, Schaller A, Schumperli D, Gray NK, Muller B. The stem-loop binding protein stimulates histone translation at an early step in the initiation pathway. RNA. 2005 Jul;11(7):1030-1042.

[81] Huang Y, Gattoni R, Stevenin J, Steitz JA. SR splicing factors serve as adapter proteins for TAP-dependent mRNA export. Mol Cell. 2003 Mar;11(3):837-843. 
[82] Whitfield ML, Kaygun H, Erkmann JA, Townley-Tilson WH, Dominski Z, Marzluff WF. SLBP is associated with histone mRNA on polyribosomes as a component of the histone mRNP. Nucleic Acids Res. 2004;32(16):4833-4842.

[83] Reis CC, Campbell JL. Contribution of Trf4/5 and the nuclear exosome to genome stability through regulation of histone mRNA levels in Saccharomyces cerevisiae. Genetics. 2007 Mar;175(3):993-1010.

[84] Herrero AB, Moreno S. Lsm1 promotes genomic stability by controlling histone mRNA decay. EMBO J. 2011 May 18;30(10):2008-2018.

[85] Chowdhury A, Mukhopadhyay J, Tharun S. The decapping activator Lsm1p-7pPat1p complex has the intrinsic ability to distinguish between oligoadenylated and polyadenylated RNAs. RNA. 2007 Jul;13(7):998-1016.

[86] Tharun S, He W, Mayes AE, Lennertz P, Beggs JD, Parker R. Yeast Sm-like proteins function in mRNA decapping and decay. Nature. 2000 Mar 30;404(6777):515-518.

[87] Mullen TE, Marzluff WF. Degradation of histone mRNA requires oligouridylation followed by decapping and simultaneous degradation of the mRNA both 5 ' to 3 ' and 3' to 5'. Genes Dev. 2008 Jan 1;22(1):50-65.

[88] Beggs S, James TC, Bond U. The PolyA tail length of yeast histone mRNAs varies during the cell cycle and is influenced by Sen1p and Rrp6p. Nucleic Acids Res. 2012 Mar;40(6):2700-2711.

[89] Gunjan A, Verreault A. A Rad53 kinase-dependent surveillance mechanism that regulates histone protein levels in S. cerevisiae. Cell. 2003 Nov 26;115(5):537-549.

[90] Navadgi-Patil VM, Burgers PM. Cell-cycle-specific activators of the Mec1/ATR checkpoint kinase. Biochem Soc Trans. 2011 Apr;39(2):600-605.

[91] Singh RK, Kabbaj MH, Paik J, Gunjan A. Histone levels are regulated by phosphorylation and ubiquitylation-dependent proteolysis. Nat Cell Biol. 2009 Aug;11(8): 925-933.

[92] Gunjan A, Paik J, Verreault A. The emergence of regulated histone proteolysis. Curr Opin Genet Dev. 2006 Apr;16(2):112-118.

[93] Singh RK, Liang D, Gajjalaiahvari UR, Kabbaj MH, Paik J, Gunjan A. Excess histone levels mediate cytotoxicity via multiple mechanisms. Cell Cycle. 2010 Oct 15;9(20): 4236-4244.

[94] Hanel W, Moll UM. Links between mutant p53 and genomic instability. J Cell Biochem. 2012 Feb;113(2):433-439.

[95] Ubezio P, Lupi M, Branduardi D, Cappella P, Cavallini E, Colombo V, et al. Quantitative assessment of the complex dynamics of G1, S, and G2-M checkpoint activities. Cancer Res. 2009 Jun 15;69(12):5234-5240. 
[96] Su C, Gao G, Schneider S, Helt C, Weiss C, O'Reilly MA, et al. DNA damage induces downregulation of histone gene expression through the G1 checkpoint pathway. EMBO J. 2004 Mar 10;23(5):1133-1143.

[97] Eriksson PR, Ganguli D, Nagarajavel V, Clark DJ. Regulation of histone gene expression in budding yeast. Genetics. 2012 May;191(1):7-20.

[98] Emili A, Schieltz DM, Yates JR, 3rd, Hartwell LH. Dynamic interaction of DNA damage checkpoint protein Rad53 with chromatin assembly factor Asf1. Mol Cell. 2001 Jan;7(1):13-20.

[99] Green EM, Antczak AJ, Bailey AO, Franco AA, Wu KJ, Yates JR, 3rd, et al. Replication-independent histone deposition by the HIR complex and Asf1. Curr Biol. 2005 Nov 22;15(22):2044-2049.

[100] Sutton A, Bucaria J, Osley MA, Sternglanz R. Yeast ASF1 protein is required for cell cycle regulation of histone gene transcription. Genetics. 2001 Jun;158(2):587-596.

[101] Berezney R, Dubey DD, Huberman JA. Heterogeneity of eukaryotic replicons, replicon clusters, and replication foci. Chromosoma. 2000 Mar;108(8):471-484.

[102] Leonhardt H, Rahn HP, Weinzierl P, Sporbert A, Cremer T, Zink D, et al. Dynamics of DNA replication factories in living cells. J Cell Biol. 2000 Apr 17;149(2):271-280.

[103] Paulovich AG, Hartwell LH. A checkpoint regulates the rate of progression through S phase in S. cerevisiae in response to DNA damage. Cell. 1995 Sep 8;82(5):841-847.

[104] Santocanale C, Diffley JF. A Mec1- and Rad53-dependent checkpoint controls late-firing origins of DNA replication. Nature. 1998 Oct 8;395(6702):615-618.

[105] Feijoo C, Hall-Jackson C, Wu R, Jenkins D, Leitch J, Gilbert DM, et al. Activation of mammalian Chk1 during DNA replication arrest: a role for Chk1 in the intra-S phase checkpoint monitoring replication origin firing. J Cell Biol. 2001 Sep 3;154(5):913-923.

[106] Tercero JA, Diffley JF. Regulation of DNA replication fork progression through damaged DNA by the Mec1/Rad53 checkpoint. Nature. 2001 Aug 2;412(6846):553-557.

[107] Lengauer C, Kinzler KW, Vogelstein B. Genetic instabilities in human cancers. Nature. 1998 Dec 17;396(6712):643-649.

[108] Reinberg D, Sims RJ, 3rd. de FACTo nucleosome dynamics. J Biol Chem. 2006 Aug 18;281(33):23297-23301.

[109] Formosa T. FACT and the reorganized nucleosome. Mol Biosyst. 2008 Nov;4(11): 1085-1093.

[110] Orphanides G, LeRoy G, Chang CH, Luse DS, Reinberg D. FACT, a factor that facilitates transcript elongation through nucleosomes. Cell. 1998 Jan 9;92(1):105-116.

[111] Pavri R, Zhu B, Li G, Trojer P, Mandal S, Shilatifard A, et al. Histone H2B monoubiquitination functions cooperatively with FACT to regulate elongation by RNA polymerase II. Cell. 2006 May 19;125(4):703-717. 
[112] Mason PB, Struhl K. The FACT complex travels with elongating RNA polymerase II and is important for the fidelity of transcriptional initiation in vivo. Mol Cell Biol. 2003 Nov;23(22):8323-8333.

[113] Saunders A, Werner J, Andrulis ED, Nakayama T, Hirose S, Reinberg D, et al. Tracking FACT and the RNA polymerase II elongation complex through chromatin in vivo. Science. 2003 Aug 22;301(5636):1094-1096.

[114] Jimeno-Gonzalez S, Gomez-Herreros F, Alepuz PM, Chavez S. A gene-specific requirement for FACT during transcription is related to the chromatin organization of the transcribed region. Mol Cell Biol. 2006 Dec;26(23):8710-8721.

[115] Stuwe T, Hothorn M, Lejeune E, Rybin V, Bortfeld M, Scheffzek K, et al. The FACT Spt16 "peptidase" domain is a histone H3-H4 binding module. Proc Natl Acad Sci U S A. 2008 Jul 1;105(26):8884-8889.

[116] VanDemark AP, Xin H, McCullough L, Rawlins R, Bentley S, Heroux A, et al. Structural and functional analysis of the Spt16p N-terminal domain reveals overlapping roles of yFACT subunits. J Biol Chem. 2008 Feb 22;283(8):5058-5068.

[117] Jamai A, Puglisi A, Strubin M. Histone chaperone spt16 promotes redeposition of the original h3-h4 histones evicted by elongating RNA polymerase. Mol Cell. 2009 Aug 14;35(3):377-383.

[118] Morillo-Huesca M, Maya D, Munoz-Centeno MC, Singh RK, Oreal V, Reddy GU, et al. FACT prevents the accumulation of free histones evicted from transcribed chromatin and a subsequent cell cycle delay in G1. PLoS Genet. 2010 May;6(5):e1000964.

[119] Pan X, Ye P, Yuan DS, Wang X, Bader JS, Boeke JD. A DNA integrity network in the yeast Saccharomyces cerevisiae. Cell. 2006 Mar 10;124(5):1069-1081.

[120] Hartwell LH, Kastan MB. Cell cycle control and cancer. Science. 1994 Dec 16;266(5192):1821-1828.

[121] Costanzo M, Nishikawa JL, Tang X, Millman JS, Schub O, Breitkreuz K, et al. CDK activity antagonizes Whi5, an inhibitor of G1/S transcription in yeast. Cell. 2004 Jun 25;117(7):899-913.

[122] de Bruin RA, McDonald WH, Kalashnikova TI, Yates J, 3rd, Wittenberg C. Cln3 activates G1-specific transcription via phosphorylation of the SBF bound repressor Whi5. Cell. 2004 Jun 25;117(7):887-898.

[123] Ferrezuelo F, Colomina N, Futcher B, Aldea M. The transcriptional network activated by $\mathrm{Cln} 3$ cyclin at the G1-to-S transition of the yeast cell cycle. Genome Biol. 2010;11(6):R67.

[124] Wittenberg C. Cell cycle: cyclin guides the way. Nature. 2005 Mar 3;434(7029):34-35.

[125] Schneider BL, Yang QH, Futcher AB. Linkage of replication to start by the Cdk inhibitor Sic1. Science. 1996 Apr 26;272(5261):560-562. 
[126] Schwob E, Bohm T, Mendenhall MD, Nasmyth K. The B-type cyclin kinase inhibitor p40SIC1 controls the G1 to $S$ transition in S. cerevisiae. Cell. 1994 Oct 21;79(2): 233-244.

[127] Formosa T, Ruone S, Adams MD, Olsen AE, Eriksson P, Yu Y, et al. Defects in SPT16 or POB3 (yFACT) in Saccharomyces cerevisiae cause dependence on the Hir/Hpc pathway: polymerase passage may degrade chromatin structure. Genetics. 2002 Dec; 162(4):1557-1571.

[128] Kaplan CD, Laprade L, Winston F. Transcription elongation factors repress transcription initiation from cryptic sites. Science. 2003 Aug 22;301(5636):1096-1099.

[129] Cheung V, Chua G, Batada NN, Landry CR, Michnick SW, Hughes TR, et al. Chromatin- and transcription-related factors repress transcription from within coding regions throughout the Saccharomyces cerevisiae genome. PLoS Biol. 2008 Nov 11;6(11):e277.

[130] Lycan D, Mikesell G, Bunger M, Breeden L. Differential effects of Cdc68 on cell cycleregulated promoters in Saccharomyces cerevisiae. Mol Cell Biol. 1994 Nov;14(11): 7455-7465.

[131] Takahata S, Yu Y, Stillman DJ. The E2F functional analogue SBF recruits the Rpd3(L) HDAC, via Whi5 and Stb1, and the FACT chromatin reorganizer, to yeast G1 cyclin promoters. EMBO J. 2009 Nov 4;28(21):3378-3389.

[132] Santisteban MS, Arents G, Moudrianakis EN, Smith MM. Histone octamer function in vivo: mutations in the dimer-tetramer interfaces disrupt both gene activation and repression. EMBO J. 1997 May 1;16(9):2493-2506.

[133] Olins AL, Olins DE. Spheroid chromatin units (v bodies). Science. 1974 Jan 25;183(4122):330-332.

[134] Kornberg RD. Chromatin structure: a repeating unit of histones and DNA. Science. 1974 May 24;184(4139):868-871. 